\title{
Quantifying the carbon dioxide emissions resulting from awareness-raising actions of sustainable mobility
}

\author{
Pétilin Souza ${ }^{1[0000-0001-7667-0340]}$, Filipa Paiva ${ }^{2[0000-0002-8733-3208]}$, Lígia Silva ${ }^{3[0000-0002-0199-}$ \\ ${ }^{8664]}$ and Paulo Pereira ${ }^{4[0000-0002-9377-6283]}$ \\ ${ }^{1}$ University of Minho, Rua da Universidade, 4710-057 Braga, Portugal \\ petilindesouza@gmail.com \\ ${ }^{2}$ University of Minho, Rua da Universidade, 4710-057 Braga, Portugal \\ filipa_paiva@sapo.pt \\ ${ }^{3}$ University of Minho, Rua da Universidade, 4710-057 Braga, Portugal \\ 1silva@civil.uminho.pt \\ ${ }^{4}$ University of Minho, Rua da Universidade, 4710-057 Braga, Portugal \\ ppereira@civil.uminho.pt
}

\begin{abstract}
Currently, the transport sector is a major contributor to global greenhouse gases emissions. The evaluation of projects that promote the decarbonization in cities is mainly focused on calculating the reduction of $\mathrm{CO}_{2}$ emissions. The calculation methodology takes into account the characteristics of the city car fleet where these projects are implemented. In the case of the "SchoolBus" project, promoted by the Braga Municipal Council during the 2018-2019 school year, the average value of reduction was of 34.9 tonCO 2 eq/year. The number of vehicles circulating in the study area, the emission factor related to the type of vehicle and its fuel and the distance traveled by them were the main parameters used to calculate $\mathrm{CO}_{2}$ emissions. The impacts of the "SchoolBus" project on stakeholders and awareness-raising actions of sustainable mobility can be quantified in terms of $\mathrm{CO}_{2}$, by analyzing the population's interest in joining more sustainable modes of transport. Thus, it is possible to evaluate the potential of the awareness-raising actions, applied in the study area, in the decarbonization in a larger area (i.e. the whole municipality). At the same time, it is possible to compare and analyze the calculated values in relation to the quantified potential range of effects of policy measures on $\mathrm{CO}_{2}$ emissions using transport demand for the year 2030, indicated by the European Commission and adapted to the area of study, by introducing measures of sustainable mobility in the territory.
\end{abstract}

Keywords: Cities decarbonization, Sustainable urban mobility, Public participation.

\section{Introduction}

Nowadays, people are moving from rural areas to cities in order to search better opportunities of labor. According to the study carried out by the United Nations, an urban population growth was observed in Portugal in 1995 [1]. Worldwide, it was determined that $55.7 \%$ of the population lives in urban areas, with an expected increase to $68.4 \%$ 
by 2050 [1]. However, in Portugal it is expected a future increase of $79.3 \%$ of the urban population [1]

The growth of the urban population has created impacts on the environment, whether directly or indirectly. According to IPCC [2], the direct and indirect impacts are as follows: (i) the increase in temperatures in cities; (ii) the higher concentration of air pollutants, including carbon dioxide emissions; (iii) the increase in noise, mainly from road traffic; and (iv) floods or droughts, creating water crises in urban areas [2].

Road traffic is one of the main sources of pollution, both air and noise, causing adverse effects on human health [3]. Increasingly, the combustion of fuels from road vehicles (60\% of air pollutants emitted in urban and surrounding areas) is one of the largest air pollutants .[4].

Greenhouse gases (GHG), when present in the atmosphere, absorb and emit part of the infrared radiation, making it impossible the Earth to lose heat to space. Carbon dioxide $\left(\mathrm{CO}_{2}\right)$ is a greenhouse gas, although it is not a toxic gas, and its emissions are the main cause of global warming. The increase in $\mathrm{CO}_{2}$ emissions is therefore one of the most important issues in an urban area [2] [4].

The case study of this article is based on the project developed by Braga City Council (CMB), Braga Urban Innovation Laboratory Demonstrator (BUILD), with the aim of reducing greenhouse gas emissions. The BUILD project aims to solve car traffic issues, improving the urban environment, based on the implementation of technological and innovative solutions in the city. The project also aims to raise awareness in the community, in order to make them aware of the importance of decarbonization and the consequent impact on raising quality of life. The area chosen for the implementation of the BUILD project is located in the parish of São Vicente, and there are seven educational institutions in this area.

Based on the analysis of the results of the actions carried out under the BUILD project, this study aims to quantify the $\mathrm{CO}_{2}$ emissions resulting from sustainable mobility awareness actions, analyzing and comparing the quantified values in relation to the potential $\mathrm{CO}_{2}$ emission reduction values established by the European Commission, which have been adapted to the area under study.

Currently, there are a great range of technological equipment capable of providing effective tools, such as electronic sensors to collect information on traffic and air pollution concentrations, thus enabling support for public policy decisions. However, a change in community habits is highly important in order to decarbonize the city and contribute to the reduction of environmental impacts. This change is only possible with the application of sustainable policies and through the participation of the community in this objective.

The present study evaluates different approaches of urban planning in the context of the BUILD project, in order to improve urban quality of life and mitigate the climate changes. More specifically, BUILD aims to promote sustainable and inclusive urban mobility, prioritizing pedestrian mode, cycling and public transport over individual transport, with the decarbonization of the study area as its main purpose. Moreover, the BUILD stimulates the potential of awareness actions, as well as the application of measures developed within the framework of Sustainable Mobility to reduce emissions in the study area. The influence of different approaches from BUILD project on $\mathrm{CO}_{2}$ 
emissions in the study area were compared and evaluated according to the method indicated by the European Commission, which was adapted to the study area, defined as PER Framework.

In the following sections the theoretical approach, the adopted methods, the case study exposition and the conclusions obtained from it are presented.

\subsection{Urban mobility and traffic pollution}

Across the EU cars remain the dominant mode of passenger transport and account, approximately, $12 \%$ of total carbon dioxide $\left(\mathrm{CO}_{2}\right)$ emissions, the main greenhouse gas (GHG) [5]. Economic and population growth have been the most important factors in increasing $\mathrm{CO}_{2}$ emissions from fossil fuel combustion [6]. In 2010, the transport sector accounted for $14 \%$ of total direct anthropogenic greenhouse gas emissions (gigatons of $\mathrm{CO}_{2}$-equivalent per year, $\mathrm{GtCO}_{2}$-eq/year) [2].

The GHG emissions from transport have not reduced in line with other economic sectors, although $\mathrm{CO}_{2}$ emissions of new passenger cars have been steadily decreasing since 2007, reaching an value of $118.5 \mathrm{~g} / \mathrm{km}$ in 2017 [5]. Thus, $\mathrm{CO}_{2}$ emissions per $\mathrm{km}$ decreased by $10.4 \%$ between 2012 and 2017 [5]. To decarbonize cities, increasing their resilience to climate change, it is necessary to change lifestyles and current mobility patterns, which focus on individual transport [2]. Thus, the impact on environment by choosing between more or less sustainable transportation modes represents a challenge for decarbonization.

The planning process of transportation has changed throughout time, but to improve the cities is required a careful planning [7]. Traditional urban planning was carried out by traffic engineers, focusing on traffic modes, infrastructure and transportation modals [8]. Currently, urban mobility planning is focused on people, presenting integrated actions to achieve cost-effective solutions in a balanced development of all relevant transport modes, regarding the transition towards cleaner and more sustainable transport modes. On the other hand, city planning began to be carried out by interdisciplinary teams with stakeholder involvement.

The decarbonization of cities has been materialized by several policy objectives focused on urban mobility, such as the sharp reduction in $\mathrm{CO}_{2}$ emissions from the transport sector to zero between 2040 and 2050; a marked reduction in emissions of air pollutants; almost zero fatalities in road transport in 20 to 40 years, depending on the current situation; drastic reduction of traffic congestion; improving the quality of urban life in general [7]. This shows the need to continually act on mobility in order to achieve a more sustainable scenario.

\subsection{Sustainable and Inclusive Urban Mobility as a Goal}

The year of 2015 marked a turning point towards sustainable development around the world. World leaders adopted a new global framework for sustainable development at the 70th UN General Assembly on 25 September 2015: the 2030 Agenda for Sustainable Development, based on the Sustainable Development Goals (SDGs). The 2030 
Agenda represents a commitment to eradicate poverty and achieve sustainable development by 2030 . The 17 SDGs and their 169 associated objectives are global in nature, universally applicable and interlinked [6].

The Paris Climate Agreement (COP21), the Addis Ababa Action Agenda, as an integral part of the 2030 Agenda, and the Sendai Framework for Disaster Risk Reduction also began to be implemented in 2015 [6]. The 2015 Paris Agreement represents a remarkable landmark in the global fight against climate change. In turn, the SDG 13 represents the EU's path to a low-carbon and climate resilient economy, through setting an ambitious economy-wide domestic target of reducing GHG emissions in at least $40 \%$ by 2030 . The target is based on global projections that are in line with the medium term ambition of the Paris Agreement [6].

The SDG 11 marks, in the following, the importance of the sustainable mobility, providing access to safe, affordable, accessible and sustainable transport systems for all. It also enhances inclusive and sustainable urbanization and capacity for participatory, integrated and sustainable human settlement planning and management in all countries.

Urban mobility planning is a challenging and complex task. Planners need to manage many demands at the local and international levels, such as the European climate change and energy efficiency targets. The complexity increases in the event of political change and severe financial constraints, as is the situation in many European countries today. A Sustainable Urban Mobility Plan (SUMP) contributes to achieving the European energy and climate objectives set by EU leaders [8].

A SUMP is a strategic plan aimed at improving the quality of life of cities and surrounding areas, taking into account the mobility needs of people and businesses, which is based on existing planning practices and considers the principles of integration, participation and evaluation. The basic principles of a Sustainable Urban Mobility Plan are: Long-term vision and clear implementation plan; Participatory approach; Balanced and integrated development of all modes of transport; Horizontal and vertical integration; Evaluation of current and future performance; Regular monitoring, review and reporting; and consideration of external costs for all modes of transport [8].

\subsection{Mobility Projects to Promote Decarbonization}

Gomez Echeverri [9] and Grandim [10] refer that more than 70\% of carbon dioxide emissions are produced by cities, making the discussion of urban challenges relevant to achieve a reduction in them. These urban challenges come from different dimensions, including urban infrastructure, transport, buildings and waste, presenting at the same time difficulties and opportunities at the technical and economic level [10]. Therefore, these mitigation challenges address the following levels: (i) institutions; (ii) behaviors; (iii) values; and (iv) technologies.

A relational perspective of these levels of urban dynamics allows us to understand that the various types of relationships that make up cities are what really create and change cities. Looking at how urban development is structured by its political economy and investigating how material forces and non-human agency are molding urban life, an adaptable relationship between both everyday practices and urban infra-structure 
becomes evident and results in unequal patterns of urban energy request and well-being [10].

With the implementation of new energy and mobility infrastructures in urban areas, there is potential for reducing carbon emissions [10]. Grandim et al. [10] address the complexity behind the implementation of new technologies or the investment of a public transport project but, more than that, a cultural and political social challenge.

The European Commission's report determined the expected impact of urban sustainable mobility measures on reducing $\mathrm{CO}_{2}$ emissions for urban areas and examined the NUT-3 areas for Europe in order to establish the interval of the potential impact [11]. The report sets out the following 21 sustainable mobility measures, each with 7 categories: (i) public transport services; (ii) urban logistics and distribution; (iii) mobility management; (iv) incorporation of transport modes; (v) road transport; (vi) marketing and educational campaigns; (vii) access restriction schemes. In order to quantify the defined measures, a range corresponding to the total at European level was established and, thus, the total value of the contribution of each dimension was defined for each country [11]. These dimensions address the need to replace unsustainable transport with sustainable transport. Taking this into account, the study conducted by Souza [12] defined the values adopted for the country where the area under analysis is located, and stipulated the reduction coming from the expected impact values for the dimensions of the study area [12].

In recent decades, the number of parents travelling by individual transport to take their children to school has increased substantially, thus reducing the number of journeys by students on public transport. The aim of school mobility plans is to improve accessibility to schools by enabling pupils to travel independently to schools in a sustainable and safe manner [11]. There are several alternative modes of sustainable mobility, including collective bus travel, walking, cycling or car sharing between parents, which promote more sustainable behaviour in children with regard to environmental and safety issues [11].

In 2014, in Cordoba, Spain, a 14-week free Walking School Bus pilot project was developed. This project, carried out in a public school with the participation of 450 students, and consisted in students going to school, accompanied by monitors. The monitors had access to an application that allowed them to add the children's participation data and provide the group's location.

School Mobility is an important aspect for the control of road traffic and, as well as for the mobility improvement in the city of Braga [13]. Thus, as part of the European Mobility Week, in 2017, the CMB developed activities in the city in order to experiment solutions to reduce road traffic in the BUILD area. The activities developed were the "PeddyBus" and the "SchoolBus". The "PeddyBus" activity consisted in the movement of students, in groups and under the supervision of adult volunteers, to schools. In a first trial, about 10 children participated in the activity [13]. At the same time, the pilot project "SchoolBus" was under development, and its function was the free transportation of students by bus to previously established schools, with the participation of 700 children in the project [13]. 


\section{Methods}

Several measures that change urban infrastructure or mobility patterns are good options to reduce $\mathrm{CO}_{2}$ emissions, for instance central urban areas closure for vehicles with pedestrian networks (SMM 5); integrated systems of public transportation (SMM 3); implementation of complete streets (SMM 14); scholar mobility plans (SMM 8) and implementation of low emission zones (SMM 21).

As previously mentioned, although traditional planning has a great focus on traffic, the discussion of sustainable urban mobility planning considers people as more important [8]. Therefore, it is extremely necessary to have an approach with participatory actions through a transparent relation. And so, the population and general stakeholders participate since the beginning of the plan development until the implementation phase. This participatory approach guarantee that the population own a Sustainable Urban Mobility Plan and the policies related to it [8].

The acceptance of a sustainable mobility plans, through long-term actions, and their permanence on the territory have greater chances to last with the involvement of the population [11][15]. Therefore, willing to achieve the objectives previous presented, the actions will be developed along with stakeholders to promote sustainable and inclusive urban mobility.

\subsection{Awareness-raising actions}

In order to promote the "SchoolBus" project among the scholar community, several activities aimed at the target public, were applied. The awareness-activities developed were: (i) mobility as a game; and (ii) sustainable mobility workshops. The barriers of the involvement of the population in planning are the idea of a high need of effort and time [15]. Regarding it, it is important to use approaches, such as playful participatory processes (PPP), that insure a more attractive activities and beaten these mentioned issues. A few examples of PPP are story-telling, walking activities, sketching or drawing and games [15]. Thus, regarding the awareness-raising actions, more specifically for the engagement of the students, the activity will consist in two games that address the theme of sustainable mobility, in order to disseminate this concept and, therefore, increase the perception of different modes of transport's impact on the environment.

The Sustainable Mobility Workshop (SMW) developed to reach the goals of raising awareness engaged general stakeholders, focusing on students, willing to help to transition from the ongoing mobility paradigm towards more sustainable options, , and was based on the activity developed in Sao Paulo, Brazil, by ITDP Brasil [14]. Therefore, the students were first invited to fill a board with their daily transportation mode on the commuting to school, between the options of by foot, by bicycle by motorcycle, by car, by taxi or by public transport.

To motivate the participation it is possible to apply free-style drawing, beyond the options of playing a game or drawing, since it is possible to comprehend either objects and situations in the geographic environment [15].

Regarding it, the students later should draw their route in a mental map form, considering the path from home to school. It was important to highlight a few reference 
points, as well as some obvious figures for them, like people, things or landscapes, always emphasizing their transportation mode.

In an attempt to gather more individual information, the students could share theirs drawings, by explaining to their friends their creations. At the same time, the technical team would support the description by asking some previous agreed questions, about their feeling during the journey, their routine activities meanwhile travelling, if it was pleasant for them or would they consider some aspect to change. If the students mentioned an aspect to change, they could mark in red these modifications.

To assess the impact of the actions it will be calculated the number of people who confirmed to be willing to transition towards a more sustainable transportation mode, and this quantity of people will be considered as vehicles that will no longer drive in that area, allowing the calculation of the $\mathrm{CO}_{2}$ emission reduction.

\subsection{PER Framework}

The Joint Research Centre (JRC) from the European Commission [11] calculated in their report 21 sustainable mobility measures' potential impact on reducing $\mathrm{CO}_{2}$ emissions in an urban environment, thorough defining the effects of those measures for each NUTS-3 zone in Europe. To better understand the NUTS (Nomenclature of Territorial Units for Statistics) zoning, it is a classification through a hierarchical system which separates the European Union (EU) economic territory regarding its dimensions considering different intentions (European Commission, n.d.). The division of the territory comes in basically three different levels, the first is for major socio-economic regions, the second basic regions in which the regional policies are applied, finally in a third level for small regions that need specific analysis to more accurate diagnosis. In the case of Portugal,, the division of NUTS-1 is Continent, Azores, and Madeira; NUTS-2 is five regions and two autonomous regions; finally, NUTS-3, concern groups of municipalities.

In the study of JRC [11] it was considered the demand of transportation by the year of 2030 through MODEL-T JRC, and the estimated $\mathrm{CO}_{2}$ emissions resultant for each NUTS-3 zone, in order to quantify the potential interval of policies' effects on reducing $\mathrm{CO}_{2}$ emissions. The potential effects of the policies of sustainable mobility were asset by an analysis which considered the differences between European territories and weighted scores from a group of experts regarding tendencies of transport behavior in each NUTS-3 zones. Once each European city distinguished itself for its size, density, population, and other aspects, the weighing method of scoring considered it, since it could certainly differ between cities [11]. Consequently it were analyzed different aspects of the cities, such as density, accessibility, employment, population and commuting characteristics of each particular zone.

The values presented by JRC [11] were adapted in the PER Framework (Table 1) to the dimensions of the study area. 
Table 1. PER Framework [12]

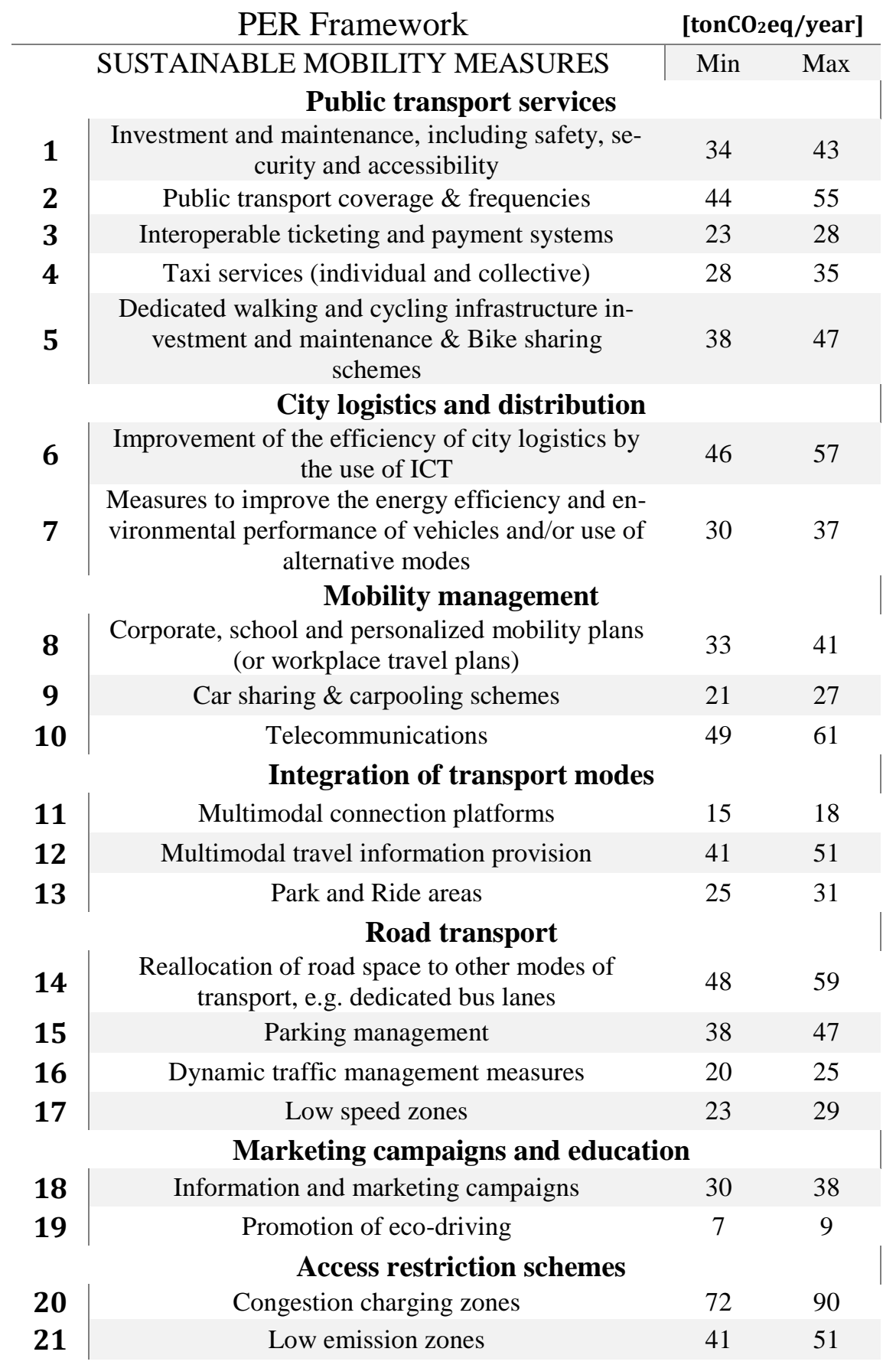


To develop this scale-down approach, Souza [16] calculated each sustainable measure contribution regarding the values range of A-S-I dimensions for Portugal potential values. As a result, Portugal represented $1.27 \%$ of the European total emission of $\mathrm{CO}_{2}$.

Afterwards, Souza [16] considered the more refined spatial dimension of subNUTS-3, that are more precise dimensions, and through the correlation of these sub zones with the Functional Urban Area (FUA) of each NUTS-3 zone it was possible to scale the values from Portugal to the dimensions of the city of Braga. The FUA analyzed in combination with NUTS-3 zones allowed a greater precision in the estimation of each transport activity specification by area. Through the method of Random Forest model, it was set a matrix of 642 (FUAs) x 21 (measures) x 3 (coefficients: A-S-I), that represented the net impact on emissions reduction across all modes in relative terms (as a share of estimated total urban transport emissions of each FUA) [17].

Some simplifications on the calculation were considered by Souza [16] since in the matter of the present study is analyzed a specific area of a city instead a comparison between different cities. Conclusively it was create a framework (PER Framework) which allows the assessment and analysis of the potential reduction of $\mathrm{CO}_{2}$ emission by each measure considered in the calculation.

The impact of the sustainable mobility measures can be asset through the PER once it calculates the quantity of $\mathrm{CO}_{2}$ that will no longer be emitted, considering the dimension of the study area in comparison with the interval set by the framework. The calculation evaluation is presented in the following section.

\section{Case Study: Awareness activities under Sustainable Mobility theme - The BUILD project}

Braga City Council developed a project in the form of Living Lab, called Braga Urban Innovation Laboratory Demonstrator (BUILD), which focused on the decarbonization of the city, allowing an urban environment accessible to innovation, through the actions of local authorities, companies, the University of Minho (UM), the International Iberian Nanotechnology Laboratory (INL), the Center for Computer Graphics (CCG), citizens and local communities. As part of this study and after the success of the "SchoolBus" pilot project carried out during the mobility week, the CMB permanently implemented the "SchoolBus" project during the 2018/2019 school year. This project consists in transporting students by bus to the respective schools, located in the city centre and belonging to the BUILD intervention area, from points located on the border of the city centre, previously defined in the project. BUILD's intervention area is located in the city of Braga, more specifically in a parish in the northeast area, São Vicente, which integrates the historical centre area and the Braga East area. The area represents one of the most recent growth areas of the city's urban area, with around 14 hectares, being highly influenced by its proximity to the city centre [14]. The north and northwest border of the area is delimited by the Regiment Street of Infantry 8 and along the east border is the cemetery of Braga and the street Dom António Bento Martins Júnior. The south border of the area is delimited by the Monte de Arcos square, the Conselheiro 
Bento Miguel street, the Conselheiro São Januário street and Dr. Domingos Soares street. According to the Geographic Information Reference Database (BGRI) and analyzing the Census 2011, there are 75 buildings in the BUILD area, 62 of which are exclusively residential and the rest with residential and commercial use. The study area presents a high difference between the areas close to the historical center, where the residential buildings are new and large, and the northern areas, where the buildings are smaller, usually single-family, and older [14]. The area under analysis has a high road traffic, due to the high concentration of educational institutions. The area contains two leisure areas, among them there is the Monte d'Arcos Square, which acts as living area, and the public park called the Pachancho Children's Park (Fig. 1).



Fig. 1. BUILD area and reference points in which 1) Dom Diogo de Sousa School 2) Leonardo Da Vinci School 3) Sá de Miranda School 4) British Institute 5) Enguardas School 6) Teresiano School 7) Francisco Sanches School[12]

The study area presents considerable road traffic congestion, mainly during the period of entry and exit of students from the various educational institutions. It also presents a problem of lack of inclusive mobility and soft modes, under the existing conditions of urban public life and access, especially in relation to abandoned and damaged public spaces. Thus, the main objective of the "SchoolBus" project is to improve accessibility, safety and, above all, the mobility in the vicinity of schools, with a perspective of decarbonizing the BUILD area. The "SchoolBus" project started in September 2018 and, in January 2019, 410 students participated in the project. The $\mathrm{CO}_{2}$ emissions calculation took into account the characteristics of the vehicle fleet of Braga, depending on the percentage of the different fuels used during the year 2017 in Portugal. Whereas in light vehicles there is a clear predominance of gas oil $(64.1 \%)$, the percentage of gasoline in 
heavy vehicles is practically insignificant, since diesel is used in $99.49 \%$ of these vehicles. In this way, all heavy vehicles were considered to use diesel (100\%). On the other hand, DEFRA [18] indicates that the amount of fuel per kilometer $(\mathrm{kg} / \mathrm{km})$ consumed by type of vehicle (light and heavy vehicles) and fuel used is 0.07 and $0.06 \mathrm{~kg} / \mathrm{km}$ for diesel and petrol vehicles, respectively, and $0.24 \mathrm{~kg} / \mathrm{km}$ for heavy (diesel) vehicles. Based on the number of vehicles circulating in the intervention area, $\mathrm{CO}_{2}$ emissions from the study area were calculated using Equation 1.

$$
\mathrm{CO}_{2} \text { emissions }\left(\mathrm{kgCO}_{2} \mathrm{e}\right)=\Sigma\left(\mathrm{N}_{\mathrm{i}, \mathrm{j}} \times \mathrm{D}_{\mathrm{i}, \mathrm{j}} \times \mathrm{EF}_{\mathrm{i}, \mathrm{j}}\right)
$$

In which:

$\mathrm{N}_{\mathrm{i}, \mathrm{j}}$ - Number of vehicles of category "i" with fuel "j"

$D_{i, j}$ - Distance traveled by vehicles of category "i" with fuel "j" $(\mathrm{km})$

$\mathrm{EF}_{\mathrm{i}, \mathrm{j}}-$ Emission factor of category "i" vehicles with "j" fuel $\left(\mathrm{kgCO}_{2}-\mathrm{eq} / \mathrm{km}\right)$

The conversion factors for calculating the greenhouse gas emissions considered the parameters set by the British Government [18][19]. Considering the vehicles fleet composition for light vehicles the emissions factors were $0.17887 \mathrm{kgCO}_{2} \mathrm{eq} / \mathrm{km}$ and 0.18568 $\mathrm{kgCO}_{2} \mathrm{eq} / \mathrm{km}$ for diesel fuel and gasoline respectively. Regarding heavy vehicles the emissions factors were $0.9339 \mathrm{kgCO}_{2} \mathrm{eq} / \mathrm{km}$ for heavy-duty diesel vehicles and 1.2194 $\mathrm{kgCO}_{2} \mathrm{eq} / \mathrm{km}$ for buses.

The reduction of $\mathrm{CO}_{2}$ emissions resulting from "SchoolBus" project was determined considering the daily number of students who used the buses assigned to the project, from the interfaces to the respective educational institutions, in each month since the beginning of the project. In order to facilitate the calculation of the distance traveled by the buses, two centroids were considered: (i) Centroid of the BUILD (CEB) Schools; (ii) Centroid of Schools not BUILD (CENB). The center of the BUILD Schools is the middle center of the bus route that passes through the Dom Diogo de Sousa School, the Leonardo Da Vinci School and the Teresiano School. The centroid of the Schools BUILD is the middle center of the bus route that passes through the School EB2,3 Francisco Sanches, Calouste Gulbenkian School and School EB2,3 André Soares. Knowing the route made by the buses, from the interfaces to the centroids, it was determined the distances traveled by them (Fig.2).

The reduction of motor vehicle traffic after the implementation of the "SchoolBus" project was obtained by considering that the number of students using the bus as equal to the number of private light vehicles that stop circulating in the BUILD area, applying the 1:1 rule. The Table 2 shows the routes traveled by buses and their distances traveled, as well as the number of private vehicles associated with the number of students using the bus. Finally, through Equation 1, the contribution of the "SchoolBus" project was calculated for the decarbonization of the BUILD area, which translated into the average annual reduction of 33.8 tonCO $\mathrm{CO}_{2}$ eq. 


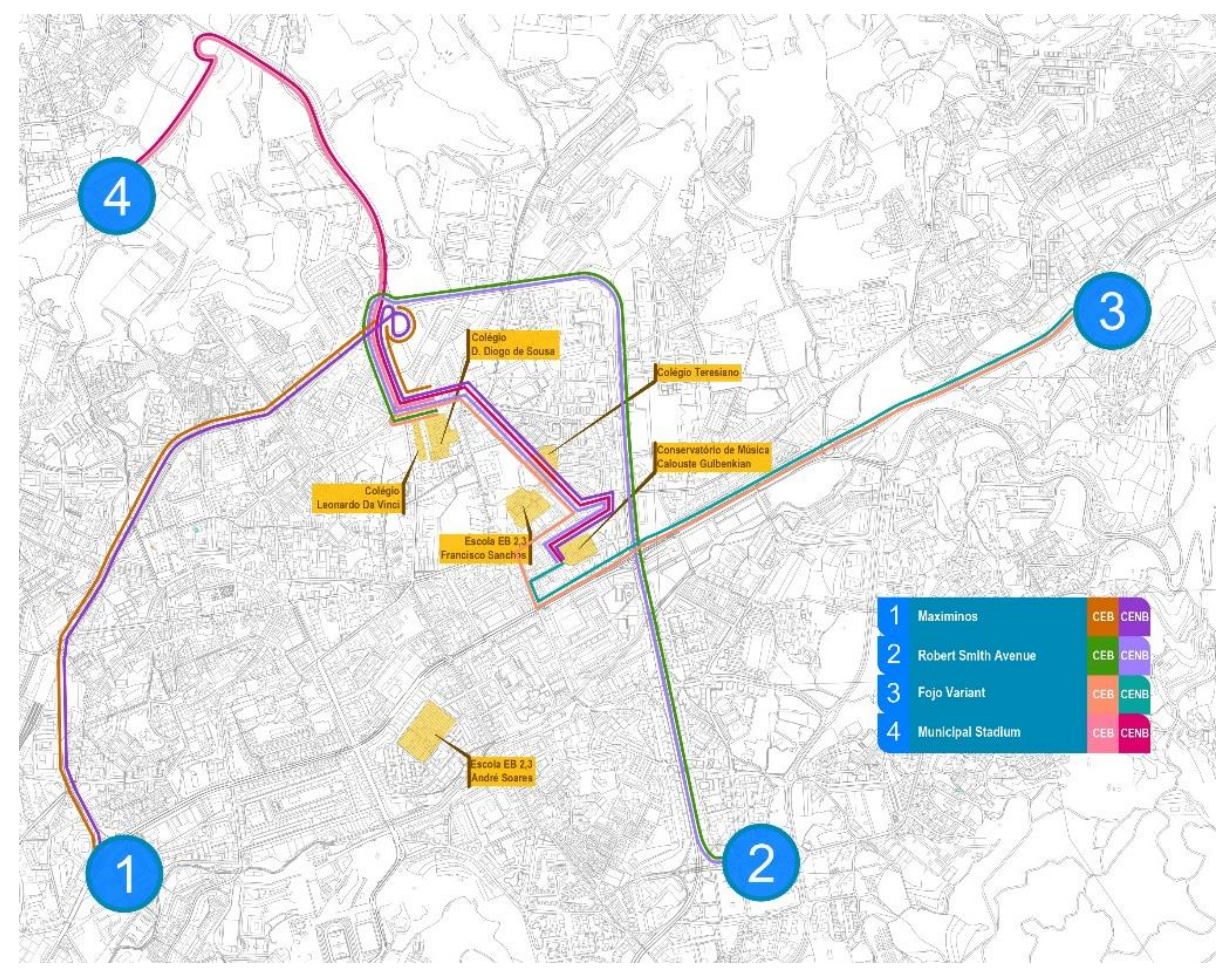

Fig. 2. Routes between interfaces and centroids considered for the calculation of $\mathrm{CO}_{2}$ emissions (Source: Authors)

Table 2. Number of vehicles associated with the number of students using School Bus and the routes and their distances traveled by buses (Source: Authors)

\begin{tabular}{c|cccc}
\multicolumn{2}{c}{ ROUTES } & & \multicolumn{2}{c}{ AVERAGE NUMBER } \\
\cline { 5 - 5 } DEPARTURE & ARRIVAL & DISTANCE & DIESEL & LIGHT \\
& & CAM & CARS & CARS \\
Municipal stadium & CENB & 10.6 & 7 & 4 \\
Municipal stadium & CEB & 8.0 & 15 & 8 \\
Fojo variant & CENB & 6.4 & 2 & 1 \\
Fojo variant & CEB & 9.4 & 9 & 5 \\
Robert Smith avenue & CENB & 10.8 & 2 & 1 \\
Robert Smith avenue & CEB & 8.2 & 35 & 19 \\
Maximinos & CENB & 11.2 & 5 & 3 \\
Maximinos & CEB & 8.6 & 5 & 3
\end{tabular}


From the 546 students involved in the awareness actions carried out, 141 students were as well in the sustainable mobility workshops from the Dom Diogo de Sousa School and the Leonardo Da Vinci School (Table 3).

Table 3. Number of stakeholders engaged in each activity (Source: Authors)

\begin{tabular}{c|cc}
\multicolumn{2}{c}{ AWARENESS-RAISING ACTIONS } & STUDENTS \\
ENGAGED
\end{tabular}

One of the awareness-raising actions was a game in which Leonardo Da Vinci school pupils, in groups of 10, had to rank which modes of transport they considered to be more and less sustainable, and which would have the greatest impact on the environment, among several pre-defined modes of transport (walking, cycling, metro, bus, motorcycle and car). This game triggered discussions among the various groups of pupils about the results they had initially considered.

Another carried out action was the game called "Big Mobility" which consisted in answering questions about mobility, in order to address concepts and clarify issues related to the environmental impact created by each mode of transport, involving students and residents in it. This game had already been developed in 2017, by the CMB, during the European Mobility Week. The BUILD project's technical team adapted the idea to the awareness-raising activities carried out, having achieved a participation of 100 students in the "Big Mobility" games.

Students who participated in the Sustainable Mobility workshops indicated that they traveled to school in private cars, as illustrated in Fig. 3. Still, 30\% of the total showed a willingness to change to a more sustainable mode of transport, of which $64 \%$ mentioned the "SchoolBus" as a choice. On the other hand, $68 \%$ of the students indicated that they enjoyed the transportation they currently use to get to school, while $64 \%$ traveled by car.

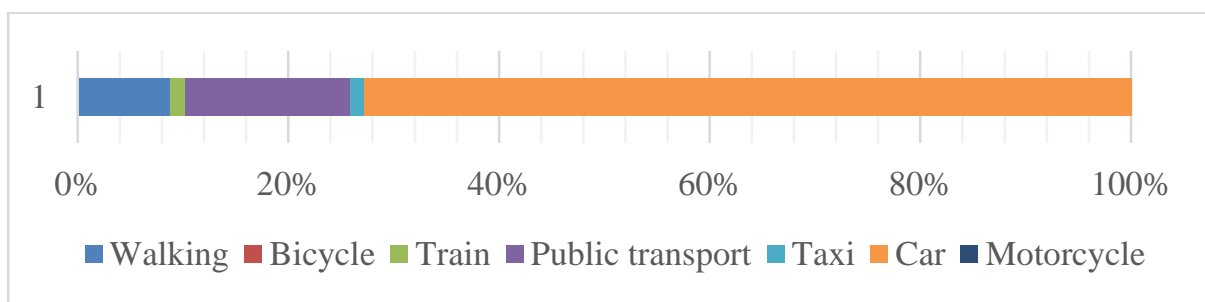

Fig. 3. Modal distribution of students on the commuting to the educational institution[12] 
In the awareness actions carried out, it was observed that $50 \%$ of the students would like the city to have less road traffic or, in some cases, that it entirely did not exist. The children mentioned the desire to have a city with less air and noise pollution, with fewer road accidents and, in this way, make the city a more attractive place with more green areas (Fig. 4).

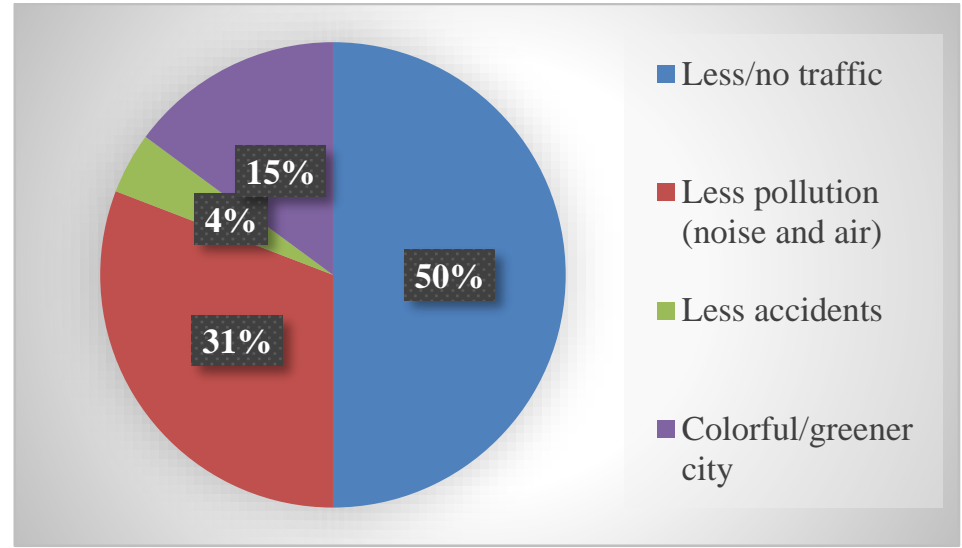

Fig. 4. How the children would like the city to be different from Mental Maps[12]

In the awareness-raising actions there was a potential increase of the $\mathrm{CO}_{2}$ emissions reduction of the "SchoolBus" project, since 27 new students showed interest in joining the project in the future. Evaluating the impact of these future inscriptions, it was verified that these 27 students would cause a decrease of $\mathrm{CO}_{2}$ emissions of 7.19 tonCO $\mathrm{C}_{2} \mathrm{eq}$, which is equivalent to $21 \%$ of the current value reached by the "SchoolBus" during this school year (reduction of $\mathrm{CO}_{2}$ emissions from 33.8 tonCO $\mathrm{CO}_{2} \mathrm{eq}$ to 40.9 tonCO $\mathrm{CO}_{2} \mathrm{eq}$ ).

The "SchoolBus" project, as started in September 2018, may have contributed to its success in achieving large numbers in reducing $\mathrm{CO}_{2}$ emissions. However, the potential impacts of awareness-raising actions in increasing the reduction of $\mathrm{CO}_{2}$ emissions allowed to achieve results closer to the maximum values of the range established by the PER Framework method, instead of approaching the minimum values, as shown in Table 4. 
Table 4. Values from PER Framework compared with calculated values of BUILD interventions[12] (Adapted)

\begin{tabular}{|c|c|c|c|c|}
\hline \multirow{2}{*}{$\begin{array}{l}\text { Sustainable } \\
\text { Mobility } \\
\text { Measure }\end{array}$} & \multirow[t]{2}{*}{ Intervention } & \multirow{2}{*}{$\begin{array}{c}\text { Interventions } \\
\text { Calculated } \\
\text { Values } \\
\text { [tonCO } \mathrm{CO}_{2} \text { eq/year] }\end{array}$} & \multicolumn{2}{|c|}{$\begin{array}{l}\text { PER Framework } \\
{\left[\text { ton } \mathrm{CO}_{2} \mathrm{eq} / \text { year] }\right.}\end{array}$} \\
\hline & & & Min. & Max. \\
\hline $\begin{array}{c}\text { Corporate, school } \\
\text { and personalized } \\
\text { mobility plans (Or } \\
\text { workplace travel } \\
\text { plans) }\end{array}$ & $\begin{array}{l}\text { "SchoolBus" - } \\
\text { Current value }\end{array}$ & 33.8 & 33 & 41 \\
\hline $\begin{array}{c}\text { Corporate, school } \\
\text { and personalized } \\
\text { mobility plans (Or } \\
\text { workplace travel } \\
\text { plans) }\end{array}$ & $\begin{array}{l}\text { "SchoolBus"- } \\
\text { Considering the } \\
\text { utilization in- } \\
\text { crease }\end{array}$ & 40.9 & 33 & 41 \\
\hline
\end{tabular}

The awareness-raising actions carried out made it possible to verify that progressive investments in Sustainable Mobility Measures, through public participation, represent a possibility of greater contribution, even more so when the objective is to achieve the decarbonization goals of a city.

\section{Conclusions}

The correlation of the city as a meeting place, that enabled the social contact of the population get lost with the raise of private transportation modes. That because it kept the population away from the urban environment as an extension of their daily life. It could only lead to an alienation of the public space, and so the scales of the city turn into impersonal relations with the built urban environment.

Considering that, there is a need of increase more active modes of transportation, that are, at the same time, more sustainable modes. This shift can approximate again the population with the city, and consequently it is important to promote a shift from expert technicians into interdisciplinary teams. It will create the possibility of the population to be heard by technical people, at the same time building up a positive relation between society and built environment. That is because it is already clear that the effectiveness of the city planning process is strictly connected with the comprehension by population that the planning is a method able to improve their quality of life.

Furthermore, the Mobility Games as a tool for public participation truly engage the stakeholders and acted as an efficient tool during the phase of motivational increase of the actions. It was a great challenge for the stakeholders to avoid mistakes while answering the questions about sustainable mobility and local traffic laws. At the same time, it was a really ludic activity for young students and helped, in a more functional perspective, in spreading the sustainable mobility concept. 
Furthermore, there is much of work in progress, since the impacts of the promoted actions in contribute to a behavioral change regarding sustainable mobility can definitely rise. Once, only $30 \%$ of the students could demonstrate the comprehension of coresponsibility on transition to a more sustainable modes of transportation, which means that they also have to change their transportation mode for a more sustainable one, although a great number of the students identified the need of a city with less traffic.

To achieve the goals of the global sustainability agenda not only governmental policies are needed, but indeed the local actions of awareness raising had great impact on behavior, since they were mainly addressed to the young population of the study area. At the same time it was an opportunity to contribute with a transformation of the technicians' perspectives, once approaching the needs of the city-users more closely. Moreover, by creating alternative solutions, such as addressing the Scholar Mobility, that was a great concern on the study area, through the project "SchoolBus", it was possible to actually impact directly issues of urban mobility. Therefore, bringing effective solutions regarding the mobility planning of the city.

Lastly, the confirmation of the continuation of the "SchoolBus" project for the scholar year of 2019/2020 creates an opportunity for future works. It will make possible the further analysis along the months of the raise tendency of students using the service, and thereupon the effective impact calculation of the project. Although the need of continuation of these actions, it is certain that this is already a piece of contribution for the sustainable mobility promotion in the city of Braga.

\section{References}

[1] United Nations, "World Urbanization Prospects: The 2018 Revision," 2018.

[2] IPCC, Climate Change 2014: Synthesis Report. Contribution of Working Groups I, II and III to the Fifth Assessment Report of the Intergovernmental Panel on Climate Change. Geneva, Switzerland: IPCC, 2014.

[3] L. T. Silva and J. F. G. Mendes, "City Noise-Air: An environmental quality index for cities," Sustain. Cities Soc., vol. 4, pp. 1-11, 2012.

[4] N. Petrovic, N. Bojovic, and J. Petrovic, "Appraisal of urbanization and traffic on environmental quality," 2016.

[5] European Union, Sustainable development in the European Union 2018. Luxembourg: Publications Office of the European Union, 2018.

[6] European Commission, "Next steps for a sustainable European future: European action for sustainability," $\operatorname{COM(2016),~p.~739,~} 2016$.

[7] W. Korver, M. Stemerding, P. Van Egmond, and F. Wefering, "CIVITAS GUIDE FOR THE URBAN TRANSPORT PROFESSIONAL - RESULTS AND LESSONS OF LONG TERM EVALUATION OF THE CIVITAS INITIATIVE," Graz, Austria, 2012.

[8] F. Wefering, S. Rupprecht, S. Bührmann, and S. Böhler-Baedeker, "Guidelines. Developing and Implementing a Sustainable Urban Mobility Plan.," 2014.

[9] L. Gomez Echeverri, "Investing for rapid decarbonization in cities," Curr. 
Opin. Environ. Sustain., vol. 30, pp. 42-51, 2018.

[10] J. Grandin, H. Haarstad, K. Kjærås, and S. Bouzarovski, "The politics of rapid urban transformation," Current Opinion in Environmental Sustainability. 2018.

[11] H. G. Lopez-Ruiz, P. Christidis, H. Demirel, and M. Kompil, "Quantifying the Effects of Sustainable Urban Mobility Plans," JRC Tech. Rep., vol. EUR 26123, 2013.

[12] P. Souza, "People-centered Urban Measures towards Sustainable Mobility," University of Minho, 2019.

[13] Braga Municipal Council, "Plano de Implementação do Braga Urban Innovation Laboratory Demonstrator (BUILD).” 2017.

[14] ITDP Brasil, "Intervenção urbana temporária (Re)pensando a rua em Santana," pp. 1-55, 2018.

[15] A. Poplin, "Playful public participation in urban planning: A case study for online serious games," 2012.

[16] P. Souza, "People-centered Urban Measures towards Sustainable Mobility," University of Minho, 2019.

[17] E. Pisoni, P. Christidis, P. Thunis, and M. Trombetti, "Evaluating the impact of 'Sustainable Urban Mobility Plans' on urban background air quality," $J$. Environ. Manage., vol. 231, no. August 2018, pp. 249-255, 2019.

[18] DEFRA, "UK Government GHG Convertion Factors for Company Reporting.," 2017.

[19] CTAC, "Assessoria técnica no âmbito da avaliação dos impactos decorrentes das ações implementadas,” Braga, 2018. 